\title{
Hot-SWV: Square Wave Voltammetry with Hot Microelectrodes
}

Ariana Frkonja-Kuczinn, Josean Y. Alicea-Salas ${ }^{\mathrm{b}}$, Netzahualcóyotl Arroyo-Currás ${ }^{\mathrm{b}, *}$, Aliaksei Boika $^{\text {a,* }}$

\begin{abstract}
Affiliations
aDepartment of Chemistry, The University of Akron, Akron, OH 44325, USA.

bepartment of Pharmacology and Molecular Sciences, Johns Hopkins University School of Medicine, Baltimore, MD 21205, USA.
\end{abstract}

\section{Table of Contents}

Description of Numerical Model ................................................................................................S2

Figure S1. Simulation geometry and associated parameters............................................S2

Table S1. Physics modules from COMSOL employed in our numerical model. .......................S3

Figure S2. Square wave function created by equation S1, with time (s) versus potential (V).....S4

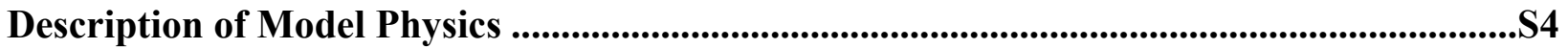

Table S2. Boundary and initial conditions for ac electric voltage (eq. S4)............................S5

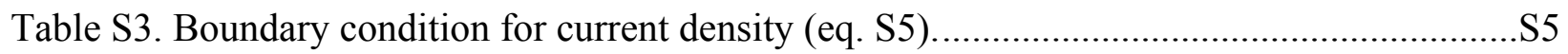

Table S4. Boundary and initial conditions for heat generation (eqs. S7 and S8).....................S6

Table S5. Boundary and initial conditions for Navier-Stokes Physics (eq. S9).........................S6

Table S6. Boundary and initial conditions for mass transfer physics (eq. S12).......................S7

Description of Mesh Elements ....................................................................................................S8

Figure S3: Mesh construction and finite element distribution in our model.............................S8

Figure S4: Temperature determined from simulations and $\Delta E_{1 / 2} \ldots \ldots \ldots \ldots \ldots \ldots \ldots \ldots \ldots$

Experimental SWV Current Sampling …................................................................................S9

Figure S5: Current sampling program employed in our simulation.......................................S9 
Figure S6: Comparison of the dimensionless SW difference current.

Figure S7: Effect of standard rate constant on SWV

Tables S7 - S9: results for $5 \mathrm{~Hz}$ hot-SWV.

Figures S8 - S10: graphed results for $5 \mathrm{~Hz}$ hot-SWV

Figure S11: Experimental and simulated hot-SWVs in $0.5 \mathrm{M} \mathrm{KCl}$ at $50 \mathrm{~Hz}$.

Tables S10 - S12: results for $50 \mathrm{~Hz}$ hot-SWV S14

Figure S12: Experimental and simulated hot-SWVs in $0.5 \mathrm{M} \mathrm{KCl}$ at $500 \mathrm{~Hz}$. S15

Tables S13 - S15: results for $500 \mathrm{~Hz}$ SWV. S16

References. S17

\section{Description of Numerical Model}

We simulated square wave voltammetry at hot microelectrodes by building a numerical model in the commercial software COMSOL Multiphysics version 5.4. In this model we simulated one ultramicroelectrode employing a 2D geometry with axial symmetry (Figure S1). The electrode was represented as a disk adjacent to an insulating rectangle representing a glass insulation.
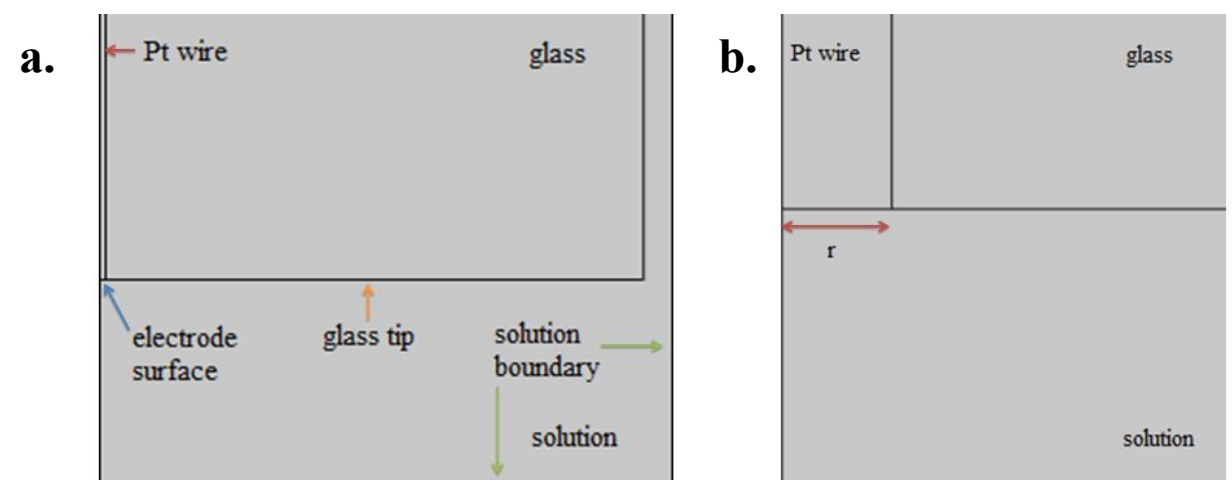

Figure S1. Simulation geometry and associated parameters.

a. Geometry of electrode and solution with labeled boundaries; b. Zoomed-in view of geometry showing the radius of the electrode wire, $r$. 
Table S1. Physics modules from COMSOL employed in our numerical model.

\begin{tabular}{|l|l|}
\hline Phenomenon & Physics interface \\
\hline ac potential distribution & electric currents \\
\hline temperature distribution & heat transfer in fluids \\
\hline electrothermal flow & laminar flow \\
\hline mass transfer & transport of diluted species \\
\hline
\end{tabular}

Our model employed the COMSOL physics modules described in Table S1. To simulate the square voltage waveform, we optimized a previously reported approach ${ }^{1}$. Briefly, the applied voltage consisted of a superposition of staircase and square wave functions (eq. S1):

$$
E=E_{\text {in }}-\left(\text { staircase }+\left(\text { wave } \times E_{S W}\right)\right) \quad(\text { eq. S1 })
$$

where $E_{\text {in }}$ is the initial potential of the square waveform and $E_{S W}$ is the square wave amplitude. We generated the staircase by employing a modulo operator - written in COMSOL as mod(a,b) - which was adjusted in magnitude by the square-wave voltage step, $E_{\text {Step }}$, and in period by the square-wave frequency, $f$ (eq. S2):

$$
\text { Staircase }=\frac{E_{\text {step }}\left(t-\bmod \left(t, \frac{1}{\bar{f}}\right)\right)}{\frac{1}{f}}
$$

To generate the square waveform, we employed a smoothed step function of sinusoidal frequency (eq. S3):

$$
\text { Wave }=f l \operatorname{smsign}(\sin (2 \pi f t), 0.000001)
$$

We chose a transition scale of $1 \times 10^{-6}$ for the step function flsmsign, which allowed us to generate waves closely approximating squares (Figure S2). 


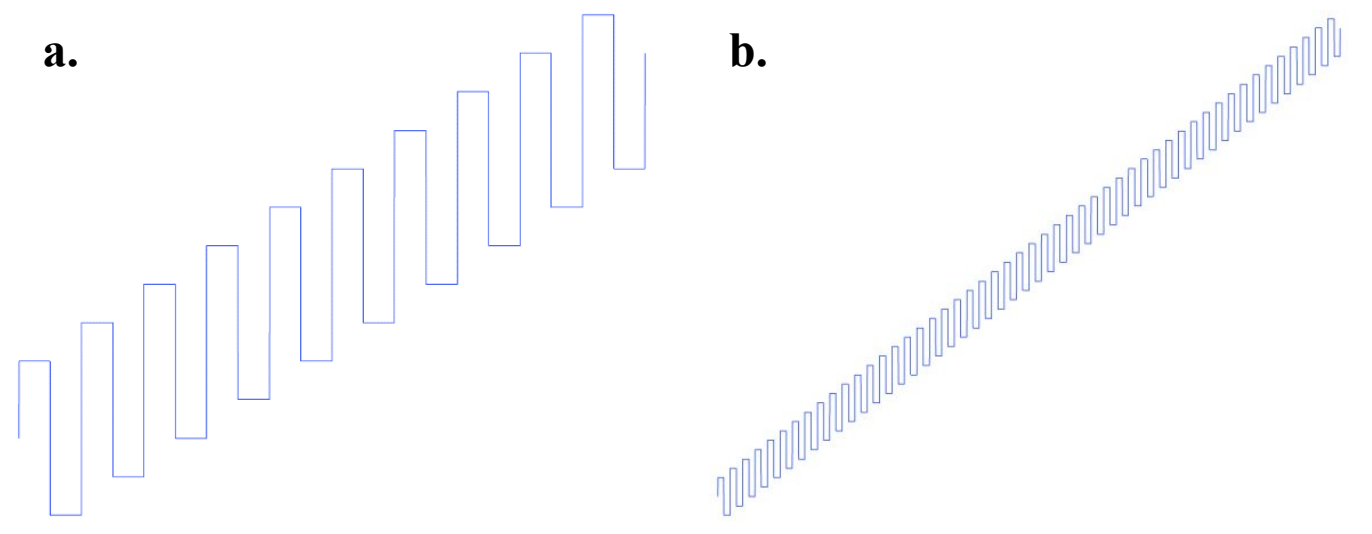

Figure S2. Square wave function created by equation S1, with time (s) versus potential (V).

a. Simulated square waveform over $t=2$ seconds; b. Simulated square waveform over $t=10$ seconds

We calculated the square waveform from eq. S1 using COMSOL's analytic function.

\section{Description of Model Physics}

Our electrode-heating approach involves applying an ac waveform to the ultramicroelectrode. This action increases the mass transfer of the redox species moving from the bulk solution to the electrode surface. To account for this and other electrokinetic phenomena, we included the following physics in our model (Table S1): ac potential distribution, temperature distribution, electrothermal flow of the solution, and mass transfer of the redox species.

We solved the ac potential distribution in solution using COMSOL's electric currents module, in which the electric potential $V$ is defined by the relationship (eq. S4):

$$
\mathbf{E}=-\nabla V
$$

where $\mathbf{E}$ is the solution's electric field density. We solved the current density $\mathbf{J}$ employing a relationship between $\mathbf{E}$ (from eq. S4) and the electrical conductivity $\sigma$ according to the point form of Ohm's law:

$$
\mathbf{J}=\sigma \mathbf{E}+\mathbf{J}_{\mathbf{e}}
$$


where $\mathbf{J}_{\mathbf{e}}$ is an externally generated current density. To handle current sources, it can be generalized from the static form of continuity that:

$$
\nabla \cdot \mathbf{J}=Q_{j, V}
$$

where $Q_{j, v}$ is a current source on the boundary. Following this analysis, we summarize boundary and initial conditions for equations S4 and S5 in Tables S2 and S3, respectively.

Table S2. Boundary and initial conditions for ac electric voltage (eq. S4).

\begin{tabular}{|l|l|}
\hline Boundary condition & Location \\
\hline $\mathrm{V}=\mathrm{V}_{0}$ & electrode surface \\
\hline Initial condition & Location \\
\hline $\mathrm{V}=0$ & solution \\
\hline
\end{tabular}

Table S3. Boundary condition for current density (eq. S5).

\begin{tabular}{|l|l|}
\hline Boundary condition & Location \\
\hline $\mathbf{n} \cdot \mathbf{J}=0$ & glass edge and glass tip \\
\hline
\end{tabular}

We solved the temperature distribution using COMSOL's heat transfer in fluids module. Briefly, heat transfer is characterized by convection and conduction according to Fourier's Law (eq. S7):

$$
\rho C_{p} \frac{\partial T}{\partial t}+\rho C_{p} \overline{\mathrm{u}} \cdot \nabla T+\nabla \cdot k \nabla T=Q \quad \text { (eq. S7) }
$$

where $\rho$ is the density of the material, $C_{p}$ is the heat capacity, $T$ is the temperature, $\overline{\mathrm{u}}$ is the linear flow rate of solution, $k$ is the thermal conductivity, and $Q$ is the heat generated in solution due to ac heating. We express $Q$ as (eq. S8):

$$
Q=\sigma \exp \left(S_{i}^{s e}\left(T-T_{b}\right)\right) E^{2}
$$

where $\sigma$ is the electrical conductivity of the electrolyte at $25{ }^{\circ} \mathrm{C}, S_{i}^{s e}$ is the Soret coefficient of the supporting electrolyte (for $\mathrm{KCl}, S_{i}^{s e}=1.41 \times 10^{-3} \mathrm{~K}^{-1}$ ), and $T_{b}$ is the temperature in the bulk solution. The heat generated in solution is proportional to the electrical conductivity of the 
electrolyte solution (mainly from the supporting electrolyte), and the conductivity at elevated temperature is corrected due to the Soret diffusion of supporting electrolyte. We summarize boundary and initial conditions for heat generation (eqs. S7 and S8) in Table S4.

Table S4. Boundary and initial conditions for heat generation (eqs. S7 and S8).

\begin{tabular}{|l|l|}
\hline Boundary condition & Location \\
\hline $\mathrm{T}=\mathrm{T}_{\mathrm{b}}$ & solution boundary \\
\hline Initial condition & Location \\
\hline $\mathrm{T}=\mathrm{T}_{\mathrm{b}}$ & whole geometry \\
\hline
\end{tabular}

We employed COMSOL's laminar flow module to solve for the solution's electrothermal flow. This module enables Navier-Stokes physics (eq. S9):

$$
\rho \frac{\partial u}{\partial t}+\rho(\overline{\mathrm{u}} \cdot \nabla) \overline{\mathrm{u}}=\nabla \cdot\left[-p \mathbf{I}+\mu\left(\nabla \overline{\mathrm{u}}+(\nabla \overline{\mathrm{u}})^{T}\right)\right]+\mathbf{F} \rho \nabla \cdot(\overline{\mathrm{u}})=0
$$

where $\mathrm{p}$ is the pressure, $\mu$ is the viscosity of the supporting electrolyte, and $\mathbf{F}$ is the volume force vector, which is defined as (eq. S10):

$$
F=\frac{1}{2}\left[\left(\frac{\nabla \sigma}{\sigma}-\frac{\nabla \varepsilon}{\varepsilon}\right) \mathbf{E} \frac{\epsilon E}{1+(\omega \tau)^{2}}+\frac{1}{2}|\mathbf{E}|^{2} \nabla \varepsilon\right]
$$

where $\varepsilon$ is the permittivity of water, $\omega$ is the angular frequency of the ac waveform, and $\tau$ is the space charge relaxation time of the supporting electrolyte and is equal to $\varepsilon / \sigma$. Eq. S10 is the expression for the electrothermal force; the first term is the Coulombic force acting on an unbalanced charge and the second term is the force on a dielectric. We summarize the boundary and initial conditions for Navier-Stokes fluid flow in Table S5, where $f_{0}$ is the normal stress, which is defined by:

$$
\left[-p \mathbf{I}+\mu\left(\nabla \overline{\mathbf{u}}+(\nabla \overline{\mathbf{u}})^{T}\right)\right] \mathbf{n}=-f_{0} \mathbf{n}
$$

Table S5. Boundary and initial conditions for Navier-Stokes Physics (eq. S9).

\begin{tabular}{|l|l|}
\hline Boundary condition & Location \\
\hline
\end{tabular}




\begin{tabular}{|l|l|}
\hline $\mathrm{u}=0$ & electrode surface, glass edge and tip \\
\hline $\mathrm{f}_{0}=0$ & solution boundary \\
\hline Initial condition & Location \\
\hline $\mathrm{u}=0$ & solution \\
\hline $\mathrm{p}=0$ & solution \\
\hline
\end{tabular}

We calculated mass transport of redox species in solution using the Nernst-Planck equation (eq. S12) with Soret diffusion included (eq. S13):

$$
\begin{aligned}
& \mathbf{J}_{\mathbf{i}}=-D_{i} \nabla C_{i}-D_{i}^{T} C_{i} \nabla T+C_{i} \overline{\mathbf{u}} \\
& D_{i}^{T}=D_{i} S_{i}
\end{aligned}
$$

in which $\mathbf{J}_{\mathbf{i}}$ is the flux of redox species, $D_{i}$ is the diffusion coefficient of the redox species, $C_{i}$ is the concentration of the redox species, and $S_{i}$ is the Soret coefficient of the redox species (for $\left.\mathrm{K}_{4} \mathrm{Fe}(\mathrm{CN})_{6}, S_{i}=5.15 \times 10^{-3} \mathrm{~K}^{-1}\right)$. We did not consider mass transfer due to migration. Thus we summarize the boundary and initial conditions for mass transfer (eq. S12) in Table S6, where $\mathrm{c}_{1}$ is the concentration of the reduced form of our redox reporter, $\mathrm{K}_{4} \mathrm{Fe}(\mathrm{CN})_{6}, \mathrm{c}_{2}$ is the concentration of the oxidized form, $\mathrm{K}_{3} \mathrm{Fe}(\mathrm{CN})_{6}$, and $\mathrm{c}_{\mathrm{b}}$ is the bulk concentration.

Table S6. Boundary and initial conditions for mass transfer physics (eq. S12).

\begin{tabular}{|l|l|}
\hline Boundary condition & Location \\
\hline$-\mathbf{n} \cdot \mathbf{J}_{\mathbf{i}}=0$ & glass edge and tip \\
\hline$-\mathbf{n} \cdot \mathbf{J}_{\mathbf{i}}=\mathrm{J}_{0, \mathrm{I}} \quad\left(\right.$ where $\mathrm{J}_{0, \mathrm{cl}}=-\left(\mathrm{kf}^{*} \mathrm{c}_{1}-\mathrm{kb}^{*} \mathrm{c}_{2}\right)$ and $\mathrm{J}_{0, \mathrm{c} 2}=\left(\mathrm{kf}^{*} \mathrm{c}_{1^{-}}\right.$ & electrode surface \\
$\left.\mathrm{kb}^{*} \mathrm{c}_{2}\right)$ & \\
\hline $\mathrm{c}_{1}=\mathrm{c}_{\mathrm{b}}, \mathrm{c}_{2}=0$ & solution boundary \\
\hline Initial condition & Location \\
\hline $\mathrm{c}_{1}=\mathrm{c}_{\mathrm{b}}, \mathrm{c}_{2}=0$ & solution \\
\hline
\end{tabular}




\section{Description of Mesh Elements}

We built our finite elements employing COMSOL's "extra fine" mesh option, which generated a mesh with maximum element size of $2 \times 10^{-5} \mathrm{~m}$ and minimum element size of $7.5 \times 10^{-8} \mathrm{~m}$. Moreover, we created an edge boundary mesh on the line representing the electrode surface with maximum element size equivalent to $1 / 1000^{\text {th }}$ of the electrode radius.

a.

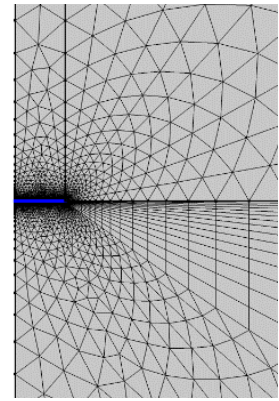

b.

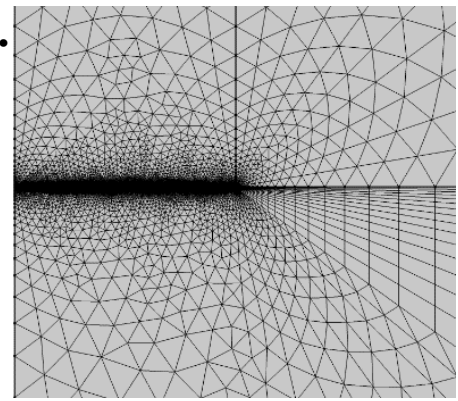

Figure S3: Mesh construction and finite element distribution in our model.

a. Mesh employed in our model with the electrode surface highlighted in blue; c. Zoomed-in view of mesh to show the finer grain produced at the electrode's edge boundary.
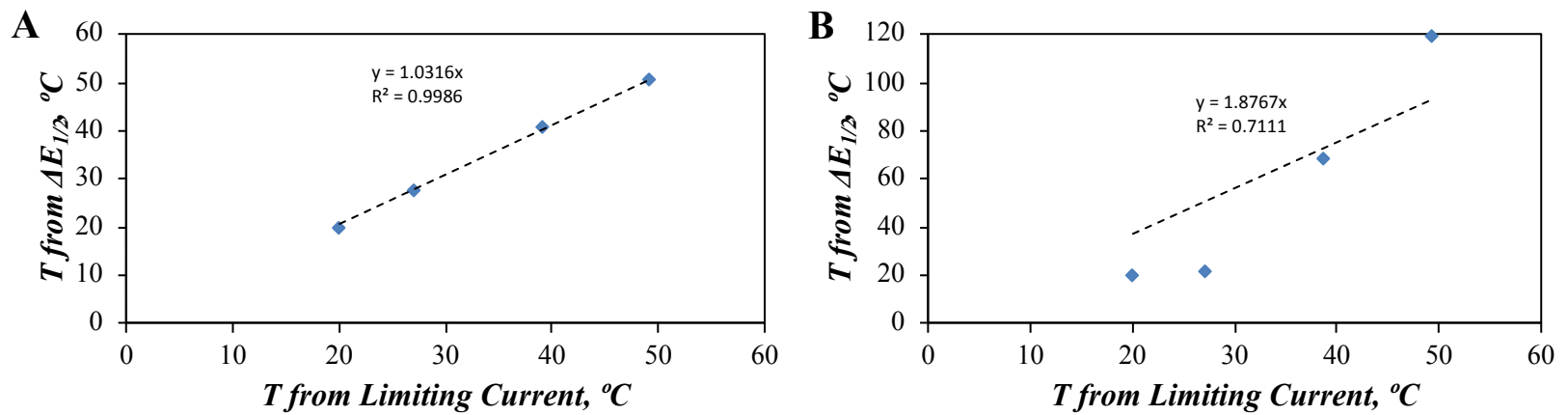

Figure S4. Temperature determined by the simulation using the limiting current value as compared to the temperature determined using the shift in the half wave potential for a solution of (A) $0.5 \mathrm{M} \mathrm{KCl}, 5 \mathrm{mM}$ $\mathrm{K}_{4} \mathrm{Fe}(\mathrm{CN})_{6}, 5 \mathrm{mM} \mathrm{KCN}$ and (B) $0.1 \mathrm{M} \mathrm{KCl}, 1 \mathrm{mM} \mathrm{K} \mathrm{Fe}_{4}(\mathrm{CN})_{6}, 1 \mathrm{mM} \mathrm{KCN}$. 


\section{Experimental SWV Current Sampling}

Our potentiostats, which are produced by CH Instruments (Austin, TX), do not sample current at the end of each square-wave pulse; instead, they average the currents over the last half of each pulse (Figure S5). We considered this in our simulations and averaged the current over the last half of each pulse.
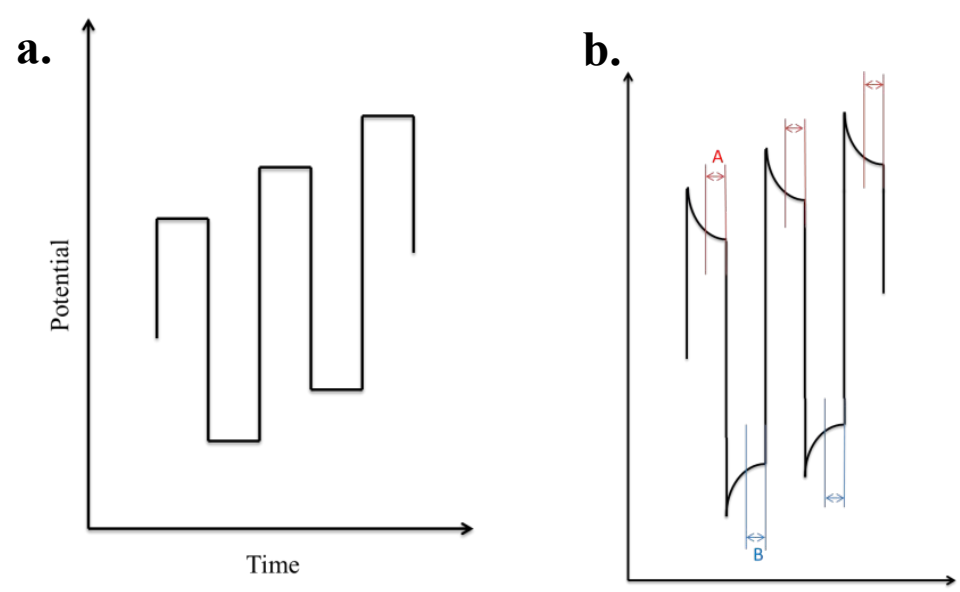

Figure S5: Current sampling program employed in our simulation.

a. Illustration of square wave voltage program over time; b. Illustration of current sampling approach employed in this work: the red A and blue B show the periods over which we averaged forward and reverse currents to match the approach used by our instrumentation. 


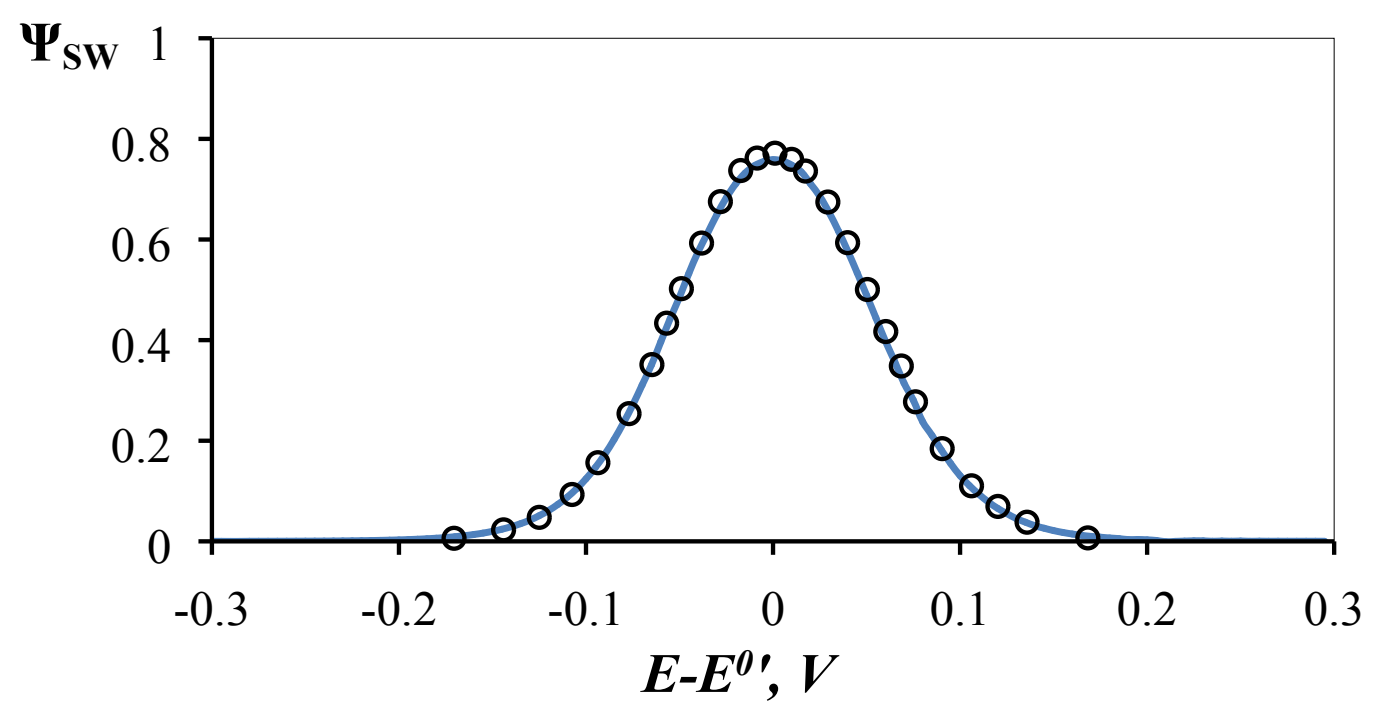

Figure S6. Comparison of the dimensionless SW difference current for the simulated data (blue curve) and the analytical solution (black circles) developed by Compton et al. (reference [26] in the main text). Conditions: one-electron reversible faradaic reaction taking place at a $20-\mu \mathrm{m}$ diam. disk electrode; concentration of the redox species $5 \mathrm{mM}$ (diffusion coefficient $1 \times 10^{-5} \mathrm{~cm}^{2} / \mathrm{s}$ ) and the $\mathrm{SW}$ parameters are $50 \mathrm{~Hz}$ frequency, $50 \mathrm{mV} \mathrm{SW}$ amplitude and $5 \mathrm{mV}$ staircase step.

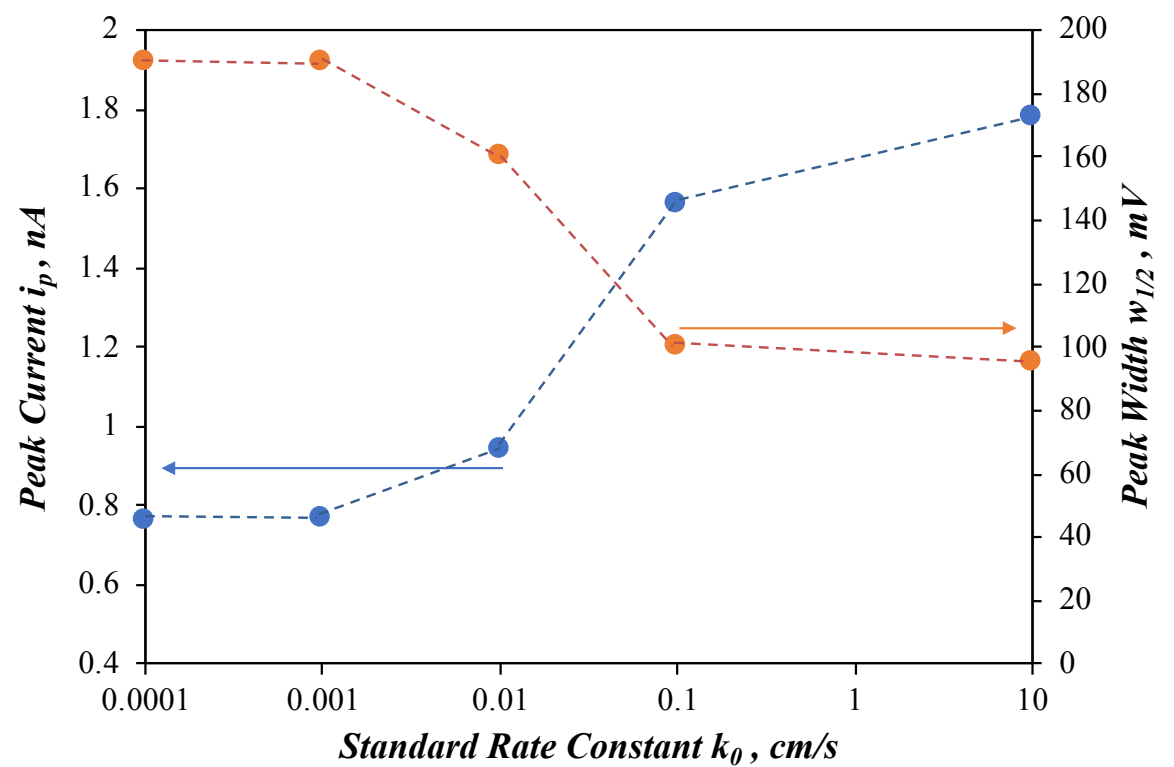

Figure S7. Effect of standard rate constant on SW differential peak current, $i_{p}$, and half-height peak width, $w_{1 / 2}$. The simulations considered a one-electron faradaic oxidation reaction performed at a $10-\mu \mathrm{m}$ diameter disk microelectrode; the concentration of the redox species was $5 \mathrm{mM}$ (diffusion coefficient $0.7 \times 10^{-5} \mathrm{~cm}^{2} / \mathrm{s}$ ) and the SWV parameters were $5 \mathrm{~Hz}$ frequency, $10 \mathrm{mV}$ amplitude and $5 \mathrm{mV}$ staircase step. 
Table S7. Peak currents, $i_{p}$, at $5 \mathrm{~Hz} \mathrm{SW}$ frequency. Based on the experimental data in Fig. 3 in the main text.

\begin{tabular}{|c|l|l|c|}
\hline $\begin{array}{c}\text { Temperature } \\
(\mathrm{C})\end{array}$ & $\begin{array}{c}\text { Experimental } \\
(\mathrm{A})\end{array}$ & $\begin{array}{c}\text { Simulated } \\
(\mathrm{A})\end{array}$ & \% Difference \\
\hline 20 & $1.73 \mathrm{E}-09$ & $1.58 \mathrm{E}-09$ & -8.7 \\
\hline 27 & $2.19 \mathrm{E}-09$ & $1.94 \mathrm{E}-09$ & -11.4 \\
\hline 39 & $4.58 \mathrm{E}-09$ & $4.86 \mathrm{E}-09$ & 6.1 \\
\hline 49 & $6.12 \mathrm{E}-09$ & $7.09 \mathrm{E}-09$ & 15.8 \\
\hline 61 & $8.13 \mathrm{E}-09$ & $1.24 \mathrm{E}-08$ & 52.5 \\
\hline
\end{tabular}

Table S8. Peak widths, $w_{1 / 2}$, at $5 \mathrm{~Hz}$ SW frequency. Based on the experimental data in Fig. 3 in the main text.

\begin{tabular}{|c|c|c|c|}
\hline $\begin{array}{c}\text { Temperature } \\
(\mathrm{C})\end{array}$ & $\begin{array}{c}\text { Experimental } \\
(\mathrm{V})\end{array}$ & $\begin{array}{c}\text { Simulated } \\
(\mathrm{V})\end{array}$ & \% Difference \\
\hline 20 & 0.0515 & 0.0500 & -3.0 \\
\hline 27 & 0.0570 & 0.0525 & -7.9 \\
\hline 39 & 0.0670 & 0.0575 & -14.2 \\
\hline 49 & 0.0835 & 0.0650 & -22.2 \\
\hline 61 & 0.1160 & 0.0775 & -33.2 \\
\hline
\end{tabular}

Table S9. Peak potentials, $\left(E_{p}-E^{0}\right)$, at $5 \mathrm{~Hz}$ SW frequency. Based on the experimental data in Fig. 3 in the main text.

\begin{tabular}{|c|c|c|c|}
\hline $\begin{array}{c}\text { Temperature } \\
(\mathrm{C})\end{array}$ & $\begin{array}{c}\text { Experimental } \\
(\mathrm{V})\end{array}$ & $\begin{array}{c}\text { Simulated } \\
(\mathrm{V})\end{array}$ & \% Difference \\
\hline 20 & 0.005 & 0.005 & 0 \\
\hline 27 & -0.010 & -0.005 & -50 \\
\hline 39 & -0.036 & -0.020 & -44 \\
\hline 49 & -0.071 & -0.025 & -65 \\
\hline 61 & -0.157 & -0.035 & -78 \\
\hline
\end{tabular}




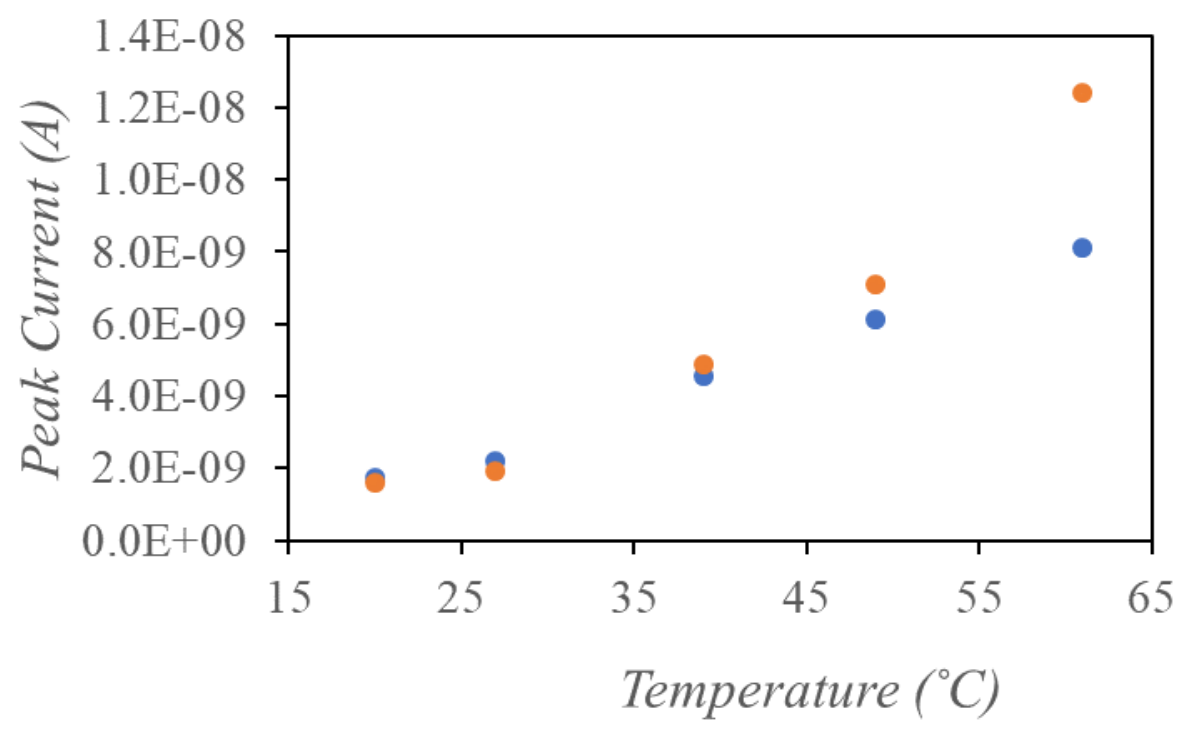

Figure S8. Peak currents, $i_{p}$, at $5 \mathrm{~Hz} \mathrm{SW}$ frequency. Based on the experimental data in Fig. 3 in the main text. Blue circles are experimental values, and orange circles are simulated values.

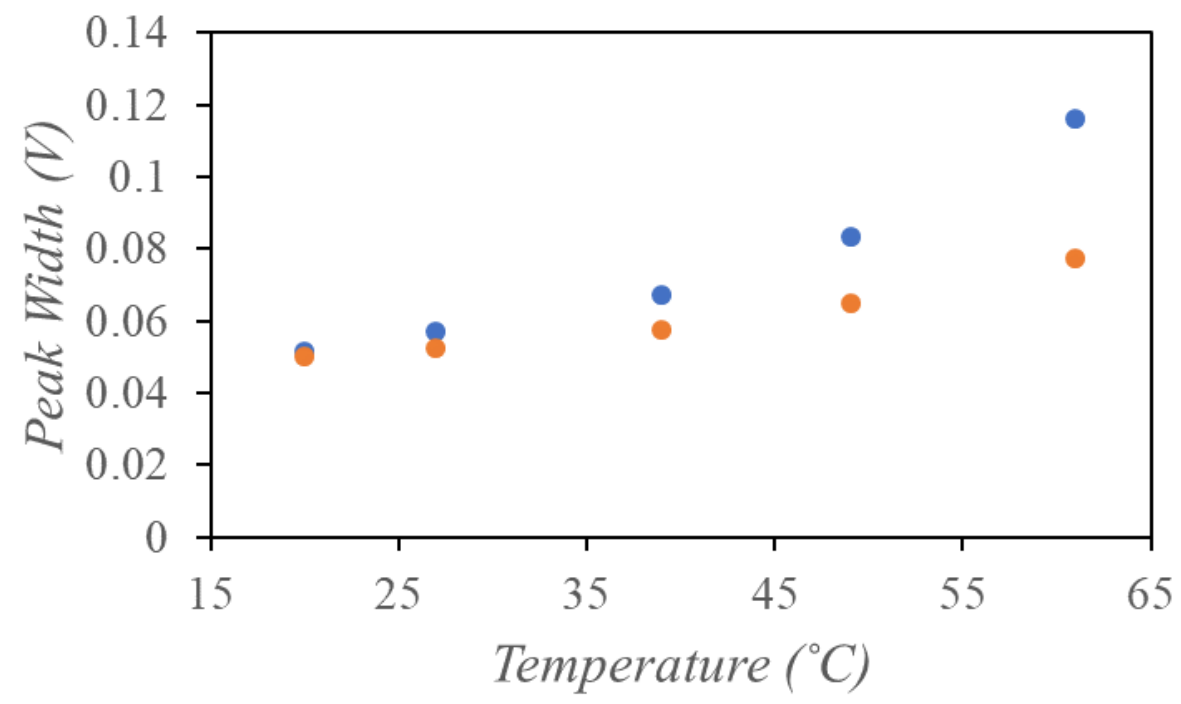

Figure S9. Peak widths, $w_{1 / 2}$, at $5 \mathrm{~Hz} \mathrm{SW}$ frequency. Based on the experimental data in Fig. 3 in the main text. Blue circles are experimental values, and orange circles are simulated values. 


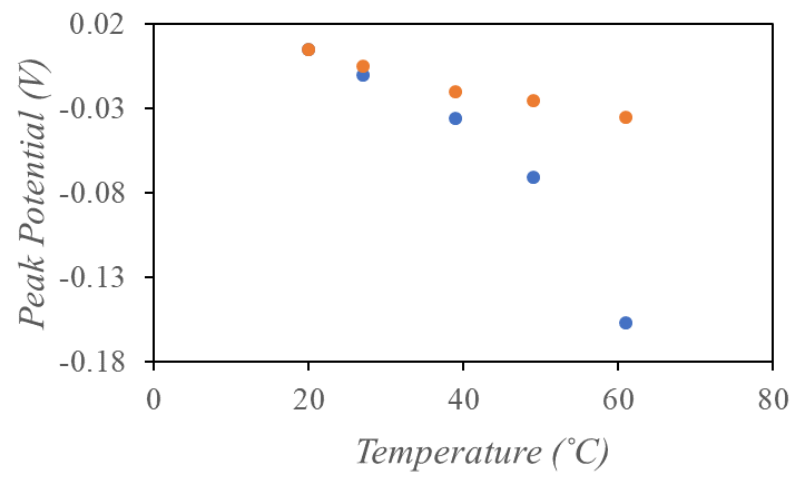

Figure S10. Peak potentials, $\left(E_{p}-E^{0}\right)$, at $5 \mathrm{~Hz} \mathrm{SW}$ frequency. Based on the experimental data in Fig. 3 in the main text. Blue circles are experimental values, and orange circles are simulated values.
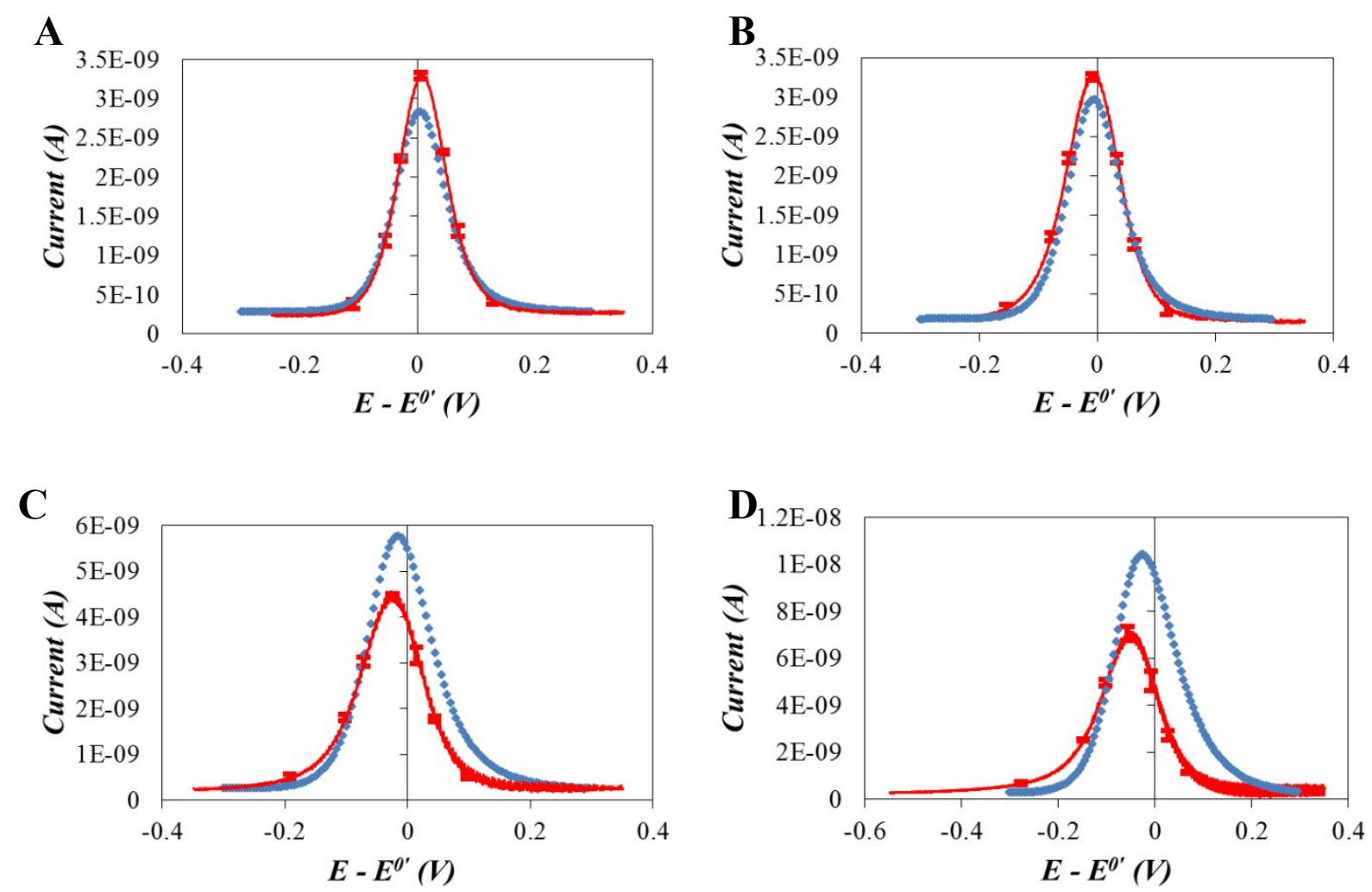

Figure S11. Experimental (red line, average of three trials) and simulated (blue dots) SWVs for 0.5 M $\mathrm{KCl}, 5 \mathrm{mM} \mathrm{K}_{4} \mathrm{Fe}(\mathrm{CN})_{6}$, and $5 \mathrm{mM} \mathrm{KCN}$ on $10 \mathrm{um} \mathrm{Pt}$ working electrode, $\mathrm{Ag} \mid \mathrm{AgCl}$ reference electrode, and $\mathrm{Pt}$ counter electrode at temperatures of A) $20^{\circ} \mathrm{C}$, B) $27^{\circ} \mathrm{C}$, C) $39^{\circ} \mathrm{C}$, and D) $49^{\circ} \mathrm{C}$. SW frequency: 50 Hz; Amplitude: 10 mV; Step potential: 0.001 V. Error bars represent one standard deviation. 
Table S10. Peak currents, $i_{p}$, at $50 \mathrm{~Hz}$ SW frequency.

\begin{tabular}{|c|c|c|c|}
\hline Temperature (C) & Experimental (A) & Simulated (A) & \% Difference \\
\hline 20 & $3.01 \mathrm{E}-09$ & $2.56 \mathrm{E}-09$ & -15.0 \\
\hline 27 & $3.03 \mathrm{E}-09$ & $2.79 \mathrm{E}-09$ & -7.92 \\
\hline 39 & $4.27 \mathrm{E}-09$ & $5.51 \mathrm{E}-09$ & 29.0 \\
\hline 49 & $6.85 \mathrm{E}-09$ & $1.01 \mathrm{E}-08$ & 47.4 \\
\hline 61 & $8.40 \mathrm{E}-09$ & $1.30 \mathrm{E}-08$ & 54.8 \\
\hline
\end{tabular}

Table S11. Peak widths, $w_{1 / 2}$, at $50 \mathrm{~Hz}$ SW frequency.

\begin{tabular}{|c|c|c|c|}
\hline Temperature (C) & Experimental (V) & Simulated (V) & \% Difference \\
\hline 20 & 0.0505 & 0.0500 & -1.0 \\
\hline 27 & 0.0555 & 0.0525 & -5.41 \\
\hline 39 & 0.0595 & 0.0600 & 0.84 \\
\hline 49 & 0.0695 & 0.0750 & 7.91 \\
\hline 61 & 0.0945 & 0.0800 & -15.3 \\
\hline
\end{tabular}

Table S12. Peak potentials $\left(E_{p}-E^{0}\right)$ at $50 \mathrm{~Hz} \mathrm{SW}$ frequency.

\begin{tabular}{|c|c|c|c|}
\hline Temperature (C) & Experimental (V) & Simulated (V) & \% Difference \\
\hline 20 & 0.005 & 0.005 & 0 \\
\hline 27 & -0.009 & -0.005 & -44 \\
\hline 39 & -0.027 & -0.015 & -44 \\
\hline 49 & -0.054 & -0.025 & -54 \\
\hline 61 & -0.097 & -0.030 & -69 \\
\hline
\end{tabular}



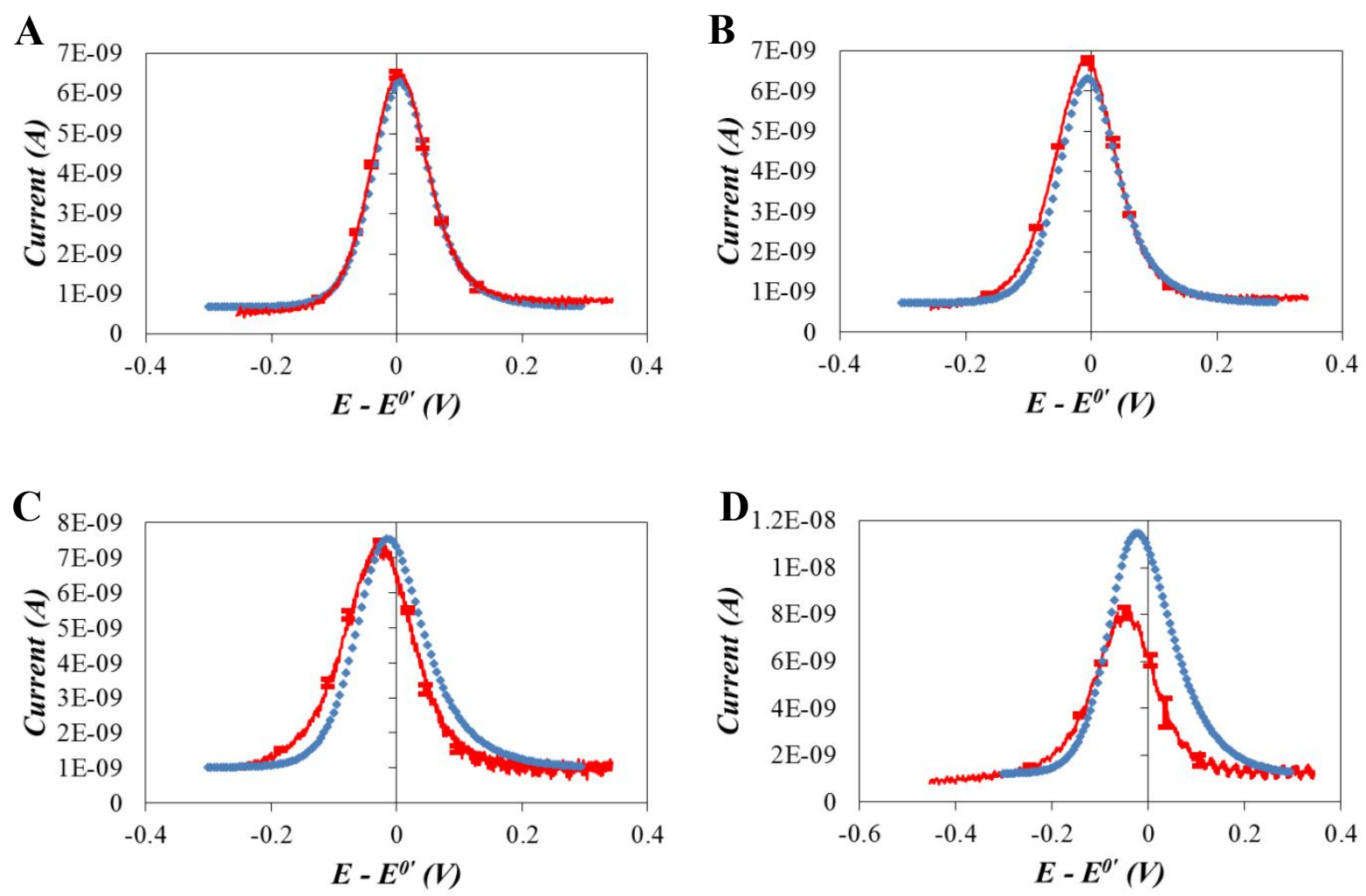

Figure S12. Experimental (red line, average of three trials) and simulated (blue dots) SWVs for $0.5 \mathrm{M}$ $\mathrm{KCl}, 5 \mathrm{mM} \mathrm{K}_{4} \mathrm{Fe}(\mathrm{CN})_{6}$, and $5 \mathrm{mM} \mathrm{KCN}$ on $10 \mathrm{um} \mathrm{Pt}$ working electrode, $\mathrm{Ag} \mid \mathrm{AgCl}$ reference electrode, and $\mathrm{Pt}$ counter electrode at temperatures of A) $20^{\circ} \mathrm{C}$, B) $27^{\circ} \mathrm{C}$, C) $39^{\circ} \mathrm{C}$, and D) $49^{\circ} \mathrm{C}$. SW frequency: 500 Hz; Amplitude: $10 \mathrm{mV}$; Step potential: $0.001 \mathrm{~V}$. Error bars represent one standard deviation. 
Table S13. Peak currents, $i_{p}$, at $500 \mathrm{~Hz}$ SW frequency.

\begin{tabular}{|c|c|c|c|}
\hline Temperature (C) & Experimental (A) & Simulated (A) & \% Difference \\
\hline 20 & $5.80 \mathrm{E}-09$ & $5.61 \mathrm{E}-09$ & -3.3 \\
\hline 27 & $6.07 \mathrm{E}-09$ & $5.60 \mathrm{E}-09$ & -7.7 \\
\hline 39 & $6.72 \mathrm{E}-09$ & $6.51 \mathrm{E}-09$ & -3.1 \\
\hline 49 & $7.56 \mathrm{E}-09$ & $1.03 \mathrm{E}-08$ & 36.2 \\
\hline 61 & $9.51 \mathrm{E}-09$ & $1.32 \mathrm{E}-08$ & 38.8 \\
\hline
\end{tabular}

Table S14. Peak widths, $w_{1 / 2}$, at $500 \mathrm{~Hz}$ SW frequency.

\begin{tabular}{|c|c|c|c|}
\hline Temperature (C) & Experimental (V) & Simulated (V) & \% Difference \\
\hline 20 & 0.0580 & 0.0550 & -5.2 \\
\hline 27 & 0.0630 & 0.0550 & -12.7 \\
\hline 39 & 0.0720 & 0.0625 & -13.2 \\
\hline 49 & 0.0805 & 0.0775 & -3.7 \\
\hline 61 & 0.0950 & 0.0825 & -13.2 \\
\hline
\end{tabular}

Table S15. Peak potentials $\left(E_{p}-E^{0}\right)$ at $500 \mathrm{~Hz}$ SW frequency

\begin{tabular}{|c|c|c|c|}
\hline Temperature (C) & Experimental (V) & Simulated (V) & \% Difference \\
\hline 20 & 0.005 & 0.005 & 0 \\
\hline 27 & -0.008 & -0.005 & -37 \\
\hline 39 & -0.031 & -0.015 & -52 \\
\hline 49 & -0.043 & -0.025 & -42 \\
\hline 61 & -0.083 & -0.030 & -64 \\
\hline
\end{tabular}




\section{References}

1. Dauphin-Ducharme, P.; Arroyo-Currás, N.; Kurnik, M.; Ortega, G.; Li, H.; Plaxco, K.W. Simulation-based approach to determining electron transfer rates using square-wave voltammetry. Langmuir 2017, 33, 18, 4407-4413. 